\title{
Intestinal Disorder
}

National Cancer Institute

\section{Source}

National Cancer Institute. Intestinal Disorder. NCI Thesaurus. Code C26801.

A non-neoplastic or neoplastic disorder that affects the small or large intestine. 